\title{
Technical Report of Accomplishments of the Weatherization Leveraging Partnership Project \\ Final Report
}

Start Date: $6 / 20 / 2002$

End Date: 9/30/2007

Margaret Power, Ph.D.

December 31, 2007

DOE Award Number: DE FC26 02NT 41649

Economic Opportunity Studies

400 North Capitol St. NW, Suite G-80

Washington, DC 20001

Disclaimer: "This report was prepared as an account of work sponsored by an agency of the United States Government. Neither the United States Government nor any agency thereof, nor any of their employees, makes any warranty, express or implied, or assumes any legal liability or responsibility for the accuracy, completeness, or usefulness of any information, apparatus, product, or process disclosed, or represents that its use would not infringe privately owned rights. Reference herein to any specific commercial product, process, or service by trade name, trademark, manufacturer, or otherwise does not necessarily constitute or imply its endorsement, recommendation, or favoring by the United States Government or any agency thereof. The views and opinions of authors expressed herein do not necessarily state or reflect those of the United States Government or any agency thereof." 


\begin{abstract}
The Weatherization Leveraging Partnership Project was established to provide three types of technical assistance support to W.A.P. network organizations seeking to achieve the Weatherization Plus goal of expanding their non-federal resources.

It provided:

1. Analysis that profiled W.A.P.-eligible household energy characteristics and finances for all in determining efficiency investment targets and goals;

2. Detailed information on leveraged partnerships linked from many sources and created a website with finding aids to meet the needs the network identified. There are five major market segments with related, but different, technical assistance needs;

3. Direct, sustained assistance in preparing strategies, analyses, and communications for a limited set of local network initiatives that were in early stages of initiating or changing their resource expansion strategies.
\end{abstract}

The Project identified trends in the challenges that weatherizers' initiatives encountered; it designed materials and tools, including the dynamic www.weatherizationplus.org website, to meet the continuing and the emerging needs. 


\section{Table of Contents}

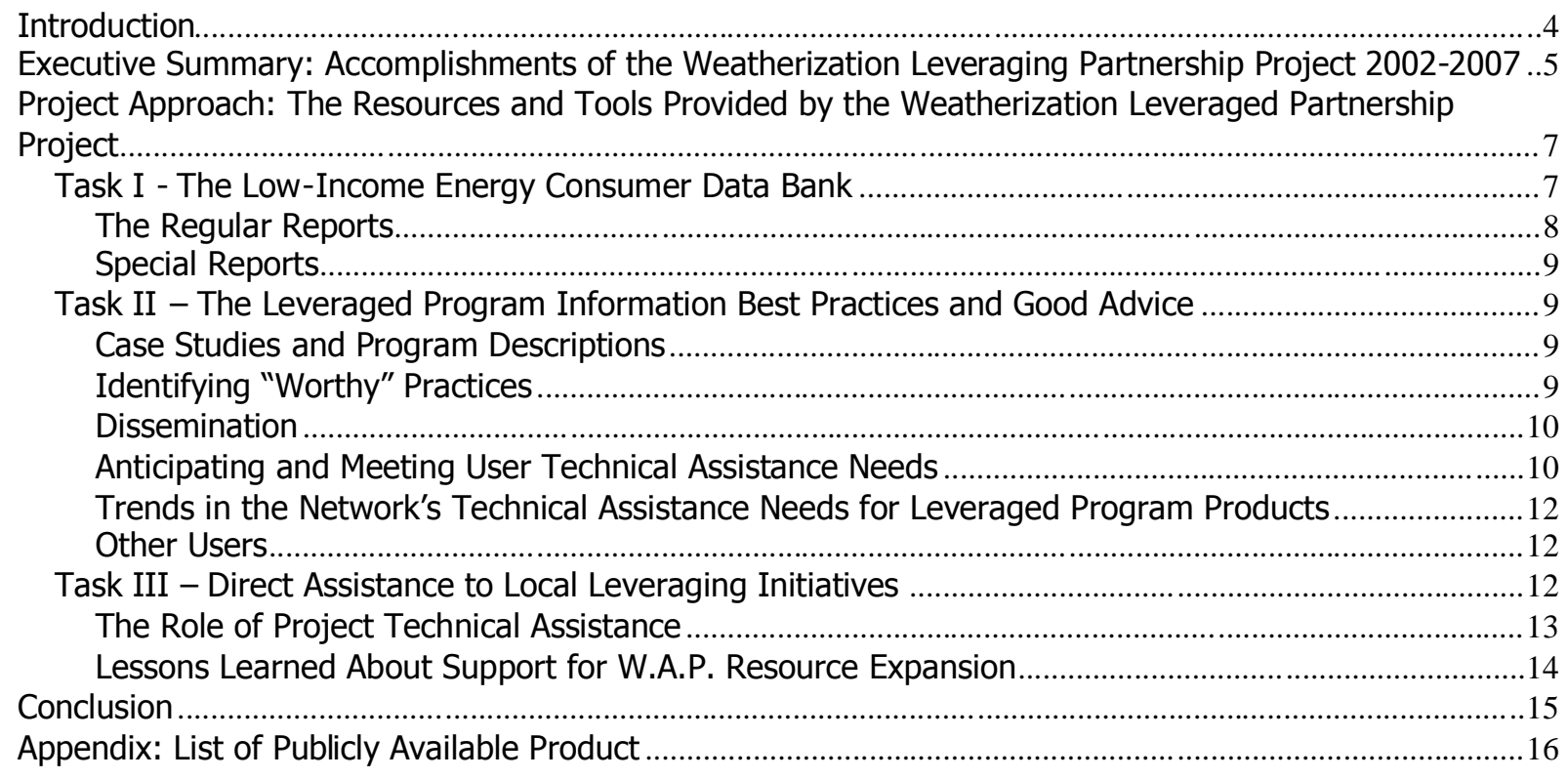

\section{Graphical Materials}

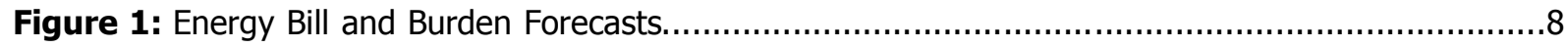

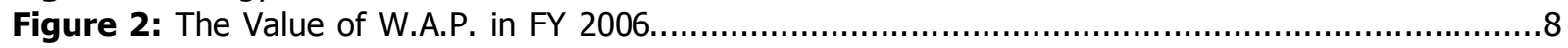

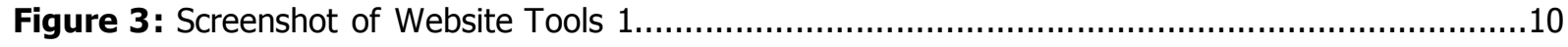

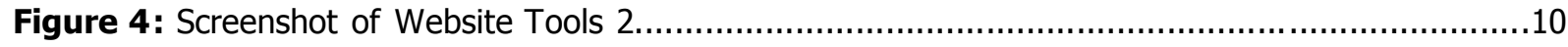




\section{Technical Report of Accomplishments of the Weatherization Leveraging Partnership Project}

\section{Introduction}

The Weatherization Leveraged Partnership Project provided three categories of technical assistance for Weatherization network organizations that are mobilizing non-federal resources and to their potential private and public sector partners. In addition, it supplied national program staff with information on leveraged partnerships, on good program practices, and on the network's progress. This technical assistance supported the implementation of two Weatherization Plus reports' Resource Expansion strategies that are one major goal of the Weatherization Plus strategy.

Over the five-year period, two changing elements affected the priorities of the project: the content of requests from W.A.P. network members shifted in response to experience and market conditions, and the Project received detailed feedback on ways to make its products easy to use. This final report describes the services provided, the lessons learned and anticipates the future leveraging-related support the network will need to implement the Resource Expansion strategies that are a major goal of the Weatherization Strategy. 


\section{Executive Summary: Accomplishments of the Weatherization Leveraging Partnership Project 2002-2007}

\section{Introduction}

The Weatherization Leveraged Partnership Project provided three categories of technical assistance for Weatherization network organizations that are mobilizing non-federal resources and to their potential private and public sector partners. In addition, it supplied national program staff with information on leveraged partnerships, on good program practices, and on the network's progress. This technical assistance supported the implementation of two Weatherization Plus reports' Resource Expansion strategies that are one major goal of the Weatherization Plus strategy.

\section{The Project:}

1. Created a "Data Bank" of Reports and Technical Papers that are used to make the case for Partnerships with Weatherization Programs

* More than 60 reports and training workshops on the energy characteristics of W.A.P.-eligible populations. Federal, state, and local network members use these statistics to demonstrate the potential for W.A.P. investments.

* More than a dozen "Quick" responses for Headquarters or PMC managers to meet their need for specific program or energy market information.

* Congressional Committees and offices have periodically requested the Project's reports

\section{Analyzed, Organized, and Disseminated Best Practices in Leveraged Programs}

* The Project staff has presented 39 workshops on its products.

$>$ Of these, 22 were part of W.A.P. network national, regional, or state training events. More than 400 W.A.P. leaders and staff have received information about how to leverage more resources for effective programs, and

$>13$ were presentations to potential partners at meetings of their associations. More than 300 individuals from utilities, regulatory bodies, nonprofits or governments learned how to and why to partner with W.A.P.

* The Project created the Weatherization Plus website implementing the Weatherization Plus Committee's recommendation to establish an online catalogue and examples of leveraged resources, case studies, and results-based "best practices". Since its March 2005 debut, more than 1000 organizations have accessed the site's collection of materials.

> Created or collected more than 46 online "Tools for Leveraging" such as templates and handbooks that network organizations can customize to fit their needs, use to design programs with proven results, and employ to support their limited development staff.

> Developed issue papers and topical outlines to help organize analyses and resources for easy access.

* In 2007 alone, national groups, including the Alliance to Save Energy, the Religious Partnership for the Environment, and the National Wildlife Federation have requested the Project's material and input on their policy development with respect to national energy legislation. 
State W.A.P. managers in NY, MA, ME, MI, TN, FL, NC, KS, CA, TX, MD, RI have received customized information from the Project, along with dozens of local agencies and their associations.

\section{Provided Direct Technical Assistance to Network Organizations and Their Potential Partners}

* The Project provided "customized" research and data about program models and the low-income energy markets upon specific requests from network member organizations. The Project's material and staff contributed to

$>$ initiating the W.A.P. network-utility dialogue in Louisiana,

$>$ helping the Arkansas network win two different utility-W.A.P. programs that will exceed $\$ 1$ million per year in FY 2008 and beyond,

$>$ helping Idaho win a $\$ 1.1$ million program,

$>$ providing data and relevant program evaluations to Illinois' low-income energy coalition and the IL state DHHS in support of winning (in FY 2008) legislation initiated to expand utility efficiency investments in Weatherization,

$>$ securing an expanded California low-income discount rate, and

> supporting Arizona CAAs' winning gas efficiency initiatives with data on other program outcomes and warm state needs.

* Project data has been cited in regulatory proceedings or coalition documents in numerous states in campaigns to win or maintain utility efficiency programs, including in IL, MA, NM and NY.

* The Project remained involved in providing support to state and/or local partners in Louisiana, Illinois, New Mexico, and Arkansas in support of ongoing leveraging initiatives over more than a year's time.

* Over the past five years, the Project also produced warm-climate program and leveraging data in response to different requests from the Governors' offices and the region's network partners.

\section{The Lessons Learned}

The lessons learned about this new category of technical assistance included the identification of five sets of "customers" for assistance with leveraging and their different needs. The final stages of the Project (and continuation work plan for FY 2008) focus product development and presentation according to their different needs.

The importance of tracking energy market and housing improvement market trends became evident as users' information and analytic requirements shifted. The Project develops tools as it anticipates and studies new developments in regulation pricing and technology that may open partnership opportunities to network organizations. 


\section{Project Approach*: The Resources and Tools Provided by the Weatherization Leveraged Partnership Project}

The Weatherization Leveraged Partnership Project tasks involved developing and disseminating three types of resources:

1. Analysis of national and regional data about the characteristics and needs of low-income consumers and their residences;

2. Information about historic or current leveraging partnerships, including information about the process of forming these partnerships and securing W.A.P.-coordinated non-federal resources.

3. Direct work for local or state W.A.P. agencies. This element was defined in the original work plan as surveys or focus groups to identify local leveraging resources and issues in program implementation and management.

In year three (FY 2005) the direction for the projects in this category changed; each year an average of two states' local agency networks indicated they needed extended staff support for their program planning and partnership development. As OMB had approved the concept of survey research as part of the national evaluation plans, the Project used the resources originally intended for such studies for staff time to meet an emerging need and support research and responsive analysis for specific projects upon request.

This final report tracks the Project work and lessons learned. It is organized by Project component and concludes with a forecast of future support needed if Weatherization resource expansion is to continue.

A list of major accomplishments follows as an Appendix.

\section{Task I - The Low-Income Energy Consumer Data Bank}

The goals of all the Data Bank products were twofold:

$>$ Define the impact of energy bills on specific low-income groups by measuring energy burdens and usage characteristics. This provided a framework for designing targeted solutions to unaffordable bills; and

$>$ Define opportunities for investment in efficiency upgrades in low-income housing.

The Data Bank materials were all designed to be used to educate decision-makers and to give a national or regional context to planning for local or utility-wide coordinated programs. They offer the Weatherization network leadership a broader context and more options for choosing the level, type, and structure of resources for cost-effective coordinated programs.

\footnotetext{
${ }^{*}$ The report format in the DOE/NETL cooperative agreement calls for a discussion of research using experimental design that is inappropriate to describe the services the Project provides. Project design products, lessons learned, and issues are described in the context of each project element.
} 


\section{The Regular Reports}

The core data came from the most recent available EIA Residential Energy Consumption Survey records. The sample of W.A.P.-eligible household data was updated each year by estimating usage in the actual weather conditions, expenditures at EIA-forecasted prices, and also the energy "burden" (bills :income) using updated Census income information for households in the lowest income quintile.
Figure 1: Energy Bill and Burden Forecasts
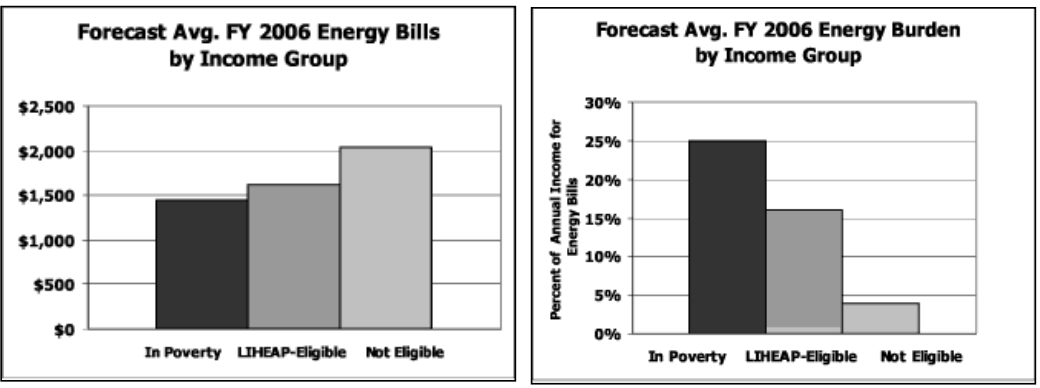

These figures are based on the prices from EIA Feb 2006 Short Term Energy Outlook and real HDD through $1 / 31 / 06$ applied to the metrics described in the evaluations of a range of Weatherization state programs found at http://weatherization .ornl.gov

Excerpt from FY 2006 Energy Bills Forecast: The Impact on Low-Income Consumers, Economic Opportunity Studies, Washington, DC. February 2006

EOS added other data sources to the analyses as they became available, including the Census data that indicates inability to pay energy bills (SIPP) and housing data (American Housing Survey). The resulting reports showed both energy burden of projected bills and the "impact" of that burden expressed as the foregone spending on other necessities and hardships that follow. The SIPP and housing survey both provided data on the correlation between housing unit defects and energy inefficiency (intensity) of homes.

Since FY 2005, EOS has partnered with ORNL and used the pricing and consumption data developed by the Lab as the base for adding updated income figures and analyzing energy markets' impact.

The national and regional reports were used by a wide range of network organizations, potential partners, and policy-makers, including governors' offices and Congressional committees.

These reports are not only helpful in calculating aggregate needs and results; they are useful in promoting good partnership program design because figures can be associated with the potential impact of program alternatives; for example, the results of investing utility funds in efficiency improvements in one type of home instead of another or instead of in payment programs. The reports suggested the indicators to use in allocating investments; for example, the relative savings from appliance replacement as compared to insulation in different regions and housing stock.

The Project's data products were circulated in the course of developing partnerships in many states, as listed in the Appendix. The Project developed training presentations and an online guide to energy data sources to allow users to "localize" regional

Figure 2: The Value of W.A.P. in FY 2006

Estimated 2005-2006 Average Savings in Homes Weatherized from 1995-2005

\begin{tabular}{|c|r|r|r|r|r|r|}
\hline $\begin{array}{c}\text { Main } \\
\text { Heat Fuel } \\
\text { Is: }\end{array}$ & $\begin{array}{c}\text { Main } \\
\text { Heat Fuel } \\
\text { Bills avg.: }\end{array}$ & $\begin{array}{r}\text { Non-Heat } \\
\text { Electricity }\end{array}$ & $\begin{array}{c}\text { All FY } \\
\text { 2006 Bills } \\
\text { Avg. }\end{array}$ & $\begin{array}{c}\text { Main Heat } \\
\text { Fuel } \\
\text { Savings }\end{array}$ & $\begin{array}{c}\text { Other } \\
\text { Electricity } \\
\text { Savings } \\
\text { (@.1) }\end{array}$ & $\begin{array}{c}\text { FY 2006 } \\
\text { Value of } \\
\text { Savings from } \\
\text { WAP Investments }\end{array}$ \\
\hline $\begin{array}{c}\text { Natural } \\
\text { Gas }\end{array}$ & $\$ 1,033$ & $\$ 684$ & $\$ 1,717$ & $\$ 392$ & $\$ 69$ & $\$ 461$ \\
\hline $\begin{array}{c}\text { Liquid } \\
\text { Propane }\end{array}$ & $\$ 1,034$ & $\$ 954$ & $\$ 2,007$ & $\$ 227$ & $\$ 95$ & $\$ 322$ \\
\hline Fuel Oil & $\$ 1,287$ & $\$ 1,005$ & $\$ 2,292$ & $\$ 386$ & $\$ 100$ & $\mathbf{\$ 4 8 6}$ \\
\hline Kerosene & $\$ 692$ & $\$ 874$ & $\$ 1,684$ & $\$ 152$ & $\$ 87$ & $\$ 229$ \\
\hline Electricity & $\$ 297$ & $\$ 803$ & $\$ 1,180$ & $\$ 118$ & NA & $\mathbf{\$ 1 1 8}$ \\
\hline
\end{tabular}

Excerpt from FY 2006 Energy Bills Forecast: The Impact on Low-Income Consumers, Economic Opportunity Studies, Washington, DC. February 2006

These figures are based on the prices from EIA Feb 2006 Short Term Energy Outlook and real HDD through 1/31/06 applied to the metrics described in the evaluations of a range of Weatherization state programs found at htpp://weatherization .ornl.gov . 
bill projections with their state and local supplier data. Reports that are not outdated, including older papers that provide a baseline for analyzing contemporary markets, remain available at the Leveraging Project website, www.weatherizationplus.org.

\section{Special Reports}

The Project's specialized reports were not only geographically specialized reports on key factors in consumers' energy usage and burdens. Network members have asked for analyses of specific populations' needs; for example, the Georgia LIHEAP director was provided with a comparison of the energy burdens of elderly consumers versus those of young families to inform decisions about benefit allocations and the need for efficiency upgrades; a coalition of Illinois advocates led by weatherizers asked for similar Midwestern statistics and for data on renters' burdens compared to homeowners'; New York weatherizers used similar project data to make the case for appropriate multi-family building investments; a British energy journal requested analysis of the usage by US households with energy burdens over $10 \%$ of income to help consideration of UK polices. Many other users and audiences are listed in the Appendix to this report.

\section{Task II - The Leveraged Program Information Best Practices and Good Advice}

\section{Case Studies and Program Descriptions}

As the Project has moved forward, an ever-growing share of its resources has been invested in this second task. The Project began by developing case studies of promising practices in mobilizing resources for housing rehabilitation that could be combined with W.A.P. and by maintaining an updated series of "lessons learned" in designing W.A.P.-utility partnerships that were offered by experienced weatherizers who participated in project focus groups or were interviewed individually. It also maintained an expanding catalogue of W.A.P.-leveraged programs selected to ensure all major types of program were represented.

\section{Identifying "Worthy" Practices}

Early work in search of validated "best practices" in the implementation of W.A.P.-coordinated leveraged resources discovered there is little independent evaluation of results. Our interviews and focus groups demonstrated that the process of winning regulatory, bureaucratic, or legislative decisions to leverage is truly idiosyncratic to the time, politics, and place of the decisions.

The Project is committed to distinguishing between empirical analysis and good advice. Therefore, we select our topics and products to primarily include work on programs that have been operating for a while, are supported and well-regarded by the weatherizers and their partners, and contain elements that may be replicable and successful elsewhere. Our materials introduce "good ideas", "peer-tested" concepts, and "winning proposals" and provide links to any objective data available as well as to colleagues with whom to discuss the costs and benefits. The decisions as to whether the practices are "best" for the user's situation are left to the customer. 


\section{Dissemination}

Dissemination of materials, whether original to the Project or developed by others, depended primarily on workshop training, participation in the network's discussion lists, through distribution of our reports, and direct contact with network organizations that were developing new or expanded partnerships. However, in early 2005, the Millennium Committee decided that collecting, cataloguing, and, where needed, creating a variety of resources should be a higher priority as a key development strategy. It also recommended that online delivery of all W.A.P. training resources be given higher priority.
Figure 3: Screenshot of Website Tools 1

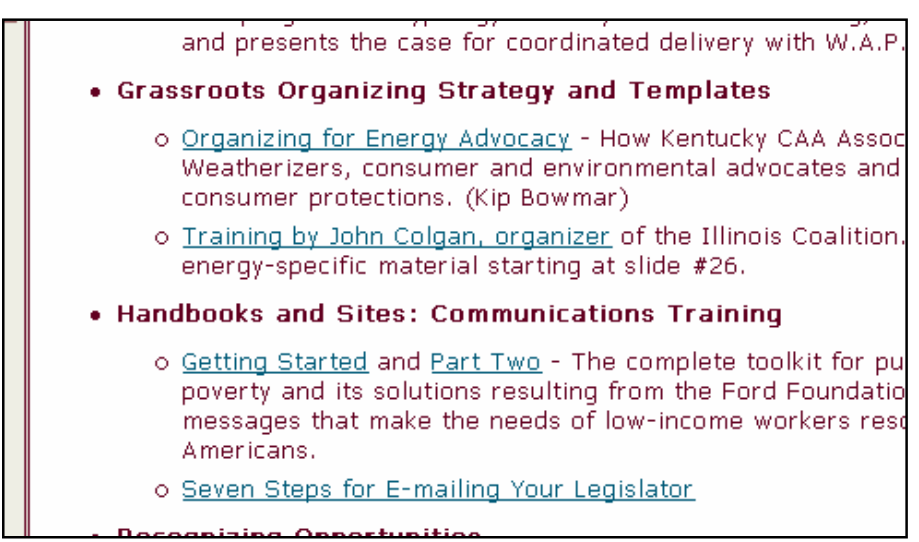

During the last half of the Project period, we devoted more resources to the development and support of the Project website, www.weatherizationplus.org, as urged by the Weatherization Plus report of 2005. Particular attention is being paid to developing user-friendly find aids that allow would-be users to identify the many kinds of materials the Project has collected and/or linked to the site.

\section{Anticipating and Meeting User Technical Assistance Needs}

As the network's experience with leveraged programs has grown, the Project has sought to capture new material that demonstrates results and to solicit opinions of weatherizers involved as to the factors that explain those outcomes.

Utility partnerships that provide ratepayer-funded investments to coordinate with W.A.P. delivery are by far the largest source of funds. By 2007, they accounted for about $\$ 250$ million in W.A.P. coordinated programs in 30 states. Over the five-year life of the project, the technical assistance needs of the users changed to reflect rapid change in utility markets and regulation. The Project responded to these specialized needs by using its collection of links to materials like reports, regulatory proceedings, news, and especially the network of expert low-income consumers' advocates to offer specific "packages" of technical resources. We added appropriate Project products, such as indicators of need, efficiency investment targets, and sample arguments for the value and results of W.A.P.-coordinated programs. The Project did not try to produce its own legal material. Our reports from the Data Bank were also used in several regulatory proceedings.

A principal Project focus when collecting results is the leveraged program's implementation/management/delivery system and how it affects the timing, costs, and benefits of the W.A.P.. Over recent years, a small body of formal evaluations of utility-W.A.P. partnerships has become available, as have more informal reviews offered as policy reports or even public testimony of the partners. The Project tracked these and linked them to
Figure 4: Screenshot of Website Tools 2

- Integrated Program Results

- Utility evaluation - Link to a selection of evaluations of lo programs, by APPRISE, Inc. The evaluated programs inclu programs and bill payment assistance programs in $\mathrm{CO}, \mathrm{N}$.

- Ohio Percentage of Income Payment Plan (PIPP) - A presa Rinebolt

- Report on 2005 Universal Service Programs \& Collection Pennsylvania Public Utility Commission

- Evaluation of Low-Income Program in Wisconsin

- Columbia Gas of Pennsylvania Inc. Universal Service and 
appropriate topic areas on the website.

The Project products include focused, short topical reports that provide a guide to the subject headings of the website and short descriptions of the items in the collection to allow users to identify only the tools or analysis that apply to their needs.

It was necessary for Project staff to identify the technical assistance tools that should make up a national collection of resources about winning resources. One clear indicator was the frequency of inquiries about topics and assistance; the Project's user community has been consistent in its expressed needs, which roughly break down into four categories:

a. The need for funds for measures that are not allowable under W.A.P. because they do not meet the energy savings SIR. Far and away the most common question is, "What funding sources can be leveraged for major home repairs and health/safety improvements?" Questions on sources of funding for appliance replacement, renewable technology purchase and water conservations measures grew more frequent over the project period. The Project is often asked to identify such sources and the details of programs that have successfully coordinated them with W.A.P..

b. The need for materials and data that have been successfully used in regulatory proceedings or legislation to win state decisions that provide more Weatherization funds. In the initial stages of an initiative to expand non-federal funding, the network's organizations lack specialized staff to prepare analysis, outreach material, talking points, and particularly the regulatory commission flings that are essential to winning approval of any utility-rate-based program. In addition to the direct help described under Task III below, the website provides a collection of introductory material, including model statutes, regulations, and commonly used filing templates, as well as links to experienced volunteers. Numerous presentations and issue papers emphasize the strategic choices that will face any new leveraging initiative and document the management experience of peers regarding the type and cost of staff time required to sustain a development initiative.

c. The third category of common questions is requests for information on specific features of tested leveraged programs. The unique expertise of the Project staff and our many advisors has been intimate knowledge of Weatherization delivery, reporting, and financial management systems. Our materials and the site itself draw attention to details of leveraged program implementation and their consequences for the results of both programs.

Examples include: How much administrative cost is contributed by utility partners in programs that work smoothly? What resulted from utility programs that had different income verification (documentation) requirements? Has any utility program ever successfully matched customers to state income maintenance program lists, and whom do we contact to find out more? Can we please have several state statutes that mandate a share of LIHEAP to W.A.P. (and how about by lunch time?)? Can you find model state W.A.P. RFPs for bids for leveraging services?

d. Finally, many questions can be summarized as, "We need more money for W.A.P.. Where can we find it?"

After several years of receiving such questions and having to drop planned work to investigate the topics, the Project organized its information and to focus on answering these requests. The answers to these questions were turned into more widely applicable memos or issue papers and posted at the site. 


\section{Trends in the Network's Technical Assistance Needs for Leveraged Program Products}

Trends in requests for assistance or training followed energy market changes and had intensified in years of W.A.P. funding decline. In 2002, most requests for technical assistance were for support of regulatory or legislative testimony regarding public benefit funds for W.A.P. as part of proceedings in states where electric prices had been deregulated. From 2004 to the end of the Project, requests for assistance in evaluating the impact of new utility business practices became increasingly common, as did requests for information and support for developing new buyer-side mechanisms such as bulk purchasing practices for Weatherization materials, for landlord partnerships, and for models of selling efficiency services to the general market.

By 2004, even more network members entered negotiations with gas utilities and regulated electric utilities to expand or initiate efficiency partnerships. In many cases, the weatherizers hoped to change utility program policies that created unnecessary costs and reduced energy and other benefits. The Project was increasingly called upon to provide our information on the features of successful programs and to connect their delivery agencies to the Weatherization partner making the inquiry.

From late 2005 forward, the Project received an accelerating flow of requests for information and expertise regarding programs and policies that protect efficiency goals in general, and for low-income consumers in particular as many states ended their deregulation "transition" periods and changed the requirements and rates that governed electric service. Further, natural gas utilities stepped up the pace of their "de-coupling" proposals that are intended to remove barriers to efficiency and several states' W.A.P. networks asked for materials so they could take positions on that issue as well.

\section{Other Users}

\section{Potential Partners}

While the primary market for the Project's products was the Weatherization network of agencies, many other groups were provided with our materials; largely they were potential partners. As indicated in the presentations section of the Appendix, utility groups invited presentations.

\section{Policy Makers and Advocates}

Several private consulting groups employed by utilities consulted the Project about program models and results. EIA and HHS jointly requested our review of the 2005 RECS survey form and our comments suggesting improvements. National efficiency advocacy groups like ACEEE and ASE requested analyses and/or presentations. Other customers also appear in the Appendix. Advocacy networks like the National Association of State Consumer Advocates, the low-income advocates' network (which includes many weatherizers), low-income housing groups, and Congressional committees, and some Governors' offices requested briefings as well as report documents as noted in the Appendix. For example, the Southern Governors' Association requested numerous regional analyses.

\section{Task III - Direct Assistance to Local Leveraging Initiatives}

In the first two years, efforts in this task focused on producing national studies of local leveraged programs and of how W.A.P. data systems incorporated leveraged resources; they are listed in the Appendix and remain at the website.

As noted above, the work plan for this section changed beginning in early 2005, and we concentrated project resources on: 
1. Assisting a few specific leveraging projects by providing research, writing, and/or more sustained, longer-term support over several months or years, including travel to meetings, presentations, and other direct contacts, and

2. Providing state-specific support or research as requested.

Over the last half of the project, we provided extensive assistance to Louisiana Community Action Partnership (and their allied utilities), the Arkansas CAA Association and the Arkansas Commission Chair, and Community Action New Mexico, as well as the support to the Illinois Coalition and state administrators mentioned above. The support ran from customized reports to draft testimony, conference presentations, facilitating meetings, telephone consultations, and linking the customer with appropriate experts and peers in the low-income networks elsewhere.

Three out of four of these initiatives have been successful. The fourth, Louisiana's resumed in late 2007 following unavoidable interruptions. We particularly encouraged warm climate states to take advantage of this category of the project's work.

Project staff set clear boundaries on its role with these specific state initiatives. We served as their expert resources to:

1. Educate network organizations and any potential partners they identified as appropriate about:

- Program alternatives and their costs and benefits,

- How W.A.P. programs are managed when coordinated with private resources,

- Legal and regulatory issues; and to

2. Organize substantive discussions with their peers in other states who have expertise and experience in options or approaches they are considers.

The Project did not represent or advocate at the state level nor in negotiations for the W.A.P. organization's proposal directly. Such a role not only requires more extended time and legal expertise, it would also make it difficult for the Project to offer future assistance with alternatives, problem-solving, or objective evaluation as the leveraged program is implemented. Project staff has provided expert testimony to regulatory bodies, but not as part of the Project's activity.

The Project' staff's functions described above are some of the tasks an informed fulltime staff person would perform if there were such a position in place as initiatives begin. Once such a person is identified, the Project's role becomes that of identifying and packaging resources appropriate to that initiative's goals, market, and context.

\section{The Role of Project Technical Assistance}

The Project's work does have two transparent biases that were openly identified in our outreach efforts and for users of our services:

1. We believe the evidence is clear that low-income efficiency leveraged investments are more costeffective when delivered by the W.A.P. organizations in coordination with the program delivery and with use of W.A.P.'s diagnostic tools; and

2. We believe that nearly all successful leveraging initiatives depend on the continuous presence of on-site staff, first to make the case to the partners and then to ensure smooth program implementation. While the leveraged funds may eventually pay for those human resources, in the early phases, the Project actively promotes expenditures of state or federal funds as the "venture capital" to start the process 


\section{Lessons Learned About Support for W.A.P. Resource Expansion}

The "market" for technical assistance to support successful leveraging is segmented along several dimensions, and the user, or customer "segments" have different technical assistance needs.

1. There are groups of network organizations with no consistent source of non-federal funding, and they are generally characterized by geography. These are:

- Warm state local agencies from Georgia west through Alabama and parts of Texas

- Rural agencies, especially the hundreds whose primary fuels are propane and power from rural electric co-ops or the TVA. (Public and rural power providers in the Pacific Northwest do offer BPA funding, however.)

These two groups and a few of their state managers need help identifying potential investment partners or in identifying legal barriers to partnership followed by help in developing a strategic plan for a leveraged initiative, including its goals, delivery mechanisms, and the results-based evidence that such investments would deliver benefits to all partners. Typically, this market has no state funds invested in leveraging activities and relies on the Project to introduce alternative sources of funding and their uses, and to develop these basic materials and, perhaps, to educate the network's members and partners. State managers in these markets are generally not encouraged to advocate for resources by their organization. About half have asked for the Project's help in defining options and good models. This market segment has demanded most of the time spent on Task III, the support for local leveraging activities.

2. Some geographic areas of states that do have W.A.P.-coordinated private leveraging programs are excluded because they are served by utilities that will not coordinate their efficiency investments with Weatherization delivery. This group's members typically request materials demonstrating the results from such duplicative programming compared to coordinated delivery; some need assistance in presenting their specific case. Others can take these materials to the instate experts at their CAA or W.A.P. association and ask for assistance in advocating for a common leveraging design for all utilities.

3. Local agencies that have limited and/or unpredictable leveraged contributions: These are agencies that tend to have won short-term programs, donations for a limited set of measures, or a limited group of homes. They ask the Project for assistance in identifying alternative models with good results and in making the case for stable and flexible expanded resources.

4. State W.A.P. networks facing dramatic changes in energy regulation or market conditions (mergers, new utility business practices or technology). They seek rapid responses on such sophisticated questions as: "In what other energy markets are consumers facing these questions and what consequences are predicted?", "Where are the analyses or forecasts of the impact and the resources we will need to cushion it?", or "Can you find us experts and advocates to work intensively on this problem?" Sometimes their needs begin with a request for the definitions of market and regulatory terminology we maintain.

5. The last large market segment of customers is the agencies state networks facing a moment of transition or review of long-standing programs. They contact the Project in search of more effective approaches or of solutions to program coordination problems; in other words, in search of our "good practices" materials and advice from the appropriate seasoned peers who participate in the low-income advocates' network.

6. There is also a "market" of W.A.P. network suppliers of our information and peer advice. They are the leveraging specialists/coordinators in states with over a decade of utility investments and related programs that have been both larger scale and effective. Project staff regularly communicates with and tracks leveraging issues with weatherizers in MA, PA, NY, IA, WI, OH, 
$\mathrm{OR}$, and WA because they provide essential new material. The consumer advocates who participate in Department-supported Low-Income Advocates group are also "suppliers" of Project material as is the LIHEAP Clearinghouse. Both sets of suppliers periodically call on the Project to help identify locations where a practice or project has been implemented or for similar "networking" assistance. Both groups use our Data Bank projects extensively and are, in that respect, customers. Members of these groups frequently join the Project staff in training events that present leveraging solutions and results.

Meeting the needs of the five user groups and the Department staff, which uses materials provided for all segments, means developing and maintaining material on a variety of funding sources (housing programs, volunteers, landlords, charities, and, of course, energy suppliers). It also means that the material must be appropriate at different levels of specificity and technicality. Finding aids must be userfriendly for the potential range of customer needs. Of great importance is informal customer service to help the user organizations define their questions as well as to collect the relevant information resources or advisors. Targeting the resources and acting as a support "staff" for the customer organizations keeps the process from failing as a result of time and skill constraints.

\section{Conclusion}

Most Weatherization network organizations lack staff which specializes in the development of new resources derived from energy supplies or housing investors. The exceptions are those that have launched generous leveraged programs financed by utility rates and coordinated with W.A.P. delivery. A majority of them would initiate a campaign to increase resources if they could. Typically, they join associations or coalitions of others with similar goals. They seek technical assistance to substitute for expert staff support in project planning design, communication, and development. Their needs change, first with the nature and degree of experience they acquire, and second with changes in energy and housing markets, which affect the availability and shape of possible mutually beneficial partnerships.

The lessons learned about this new category of technical assistance included the identification of five sets of "customers" for assistance with leveraging and their different needs. The final stages of the Project (and continuation work plan for FY 2008) focus product development and presentation according to their different needs.

The importance of tracking energy market and housing improvement market trends became evident as users information and analytic requirements shifted. The Project developed tools for its staff as it anticipates and studies new developments in regulation pricing and technology that may open partnership opportunities to network organizations. 


\section{Appendix: List of Publicly Available Products}

The numbering system matches work plan elements.

\section{Task I: The Low-Income Energy Consumer Data Bank}

\section{Task I.1}

Reports

- Overview of Poverty in America in 2004: Key Findings from the Census Bureau

- Full Funding for LIHEAP: What is it?

- Predicted 2004 Gasoline Price Increases Mean Low-Income Drivers Must Cut Travel or Lose Real Disposable Household Income

- Young or Old the Poor Face Hardship: Electricity Bills and Energy Burden by Age of Householder and Income Group

- Busting Two Myths About Energy Affordability in the Warm States

- 2001 Residential Energy Customers Paid More But Used Less Energy

- Energy Bills and Burdens by Region: 2001

- Texans' Energy and Electricity Bills: 1997

- 1997 Energy Bills, Energy Use, \& Energy Burdens of New Englanders

- Electricity Usage by Low-Income Households in the Mid-Atlantic Region

- New York and Florida 1997 Low-Income Consumer kWh usage and electricity expenditures

- 2003 Residential Energy Burden and Bills, by Income and Region

\section{Congressional Inquiries}

Aug 2003 - US House of Representatives Committee on Education and Workforce requested annual aggregate W.A.P. savings compared to LIHEAP payments and indicators of need for W.A.P.

Sep 2004 and Feb 2006 - Senate Northeast Midwest Coalition - "Outlook" paper summary. House NE-MW Coalition participated in Feb 2006.

Jul 2005 - Senate HELP Committee staff briefing on wholesale energy markets and impacts on consumers; also on potential for taxation

Nov 2005 - Data requested by NCAF for its response to the House Appropriations Committee, Interior Subcommittee

Nov 2005 - Data requested by NCAF for its response to the House Committee on Natural Resources - Outlook for Energy Bills and Burdens of Low-Income Natural Gas Consumers

Jan 2006 - Senate Energy Committee staff request list and description of W.A.P. projects that target greenhouse gas reduction or renewable energy deployment.

\section{Task I.2}

\section{National \& Regional Reports \& Forecasts}

- Forecast FY 2007 Energy Bills and Heating Bills

- Low-Income Consumers' Energy Bills and Their Impact in 2006 (Oct 2005)

- Energy Bills of Low-Income Consumers in FY 2005, The Resources Available to Help Them Pay, and the Impact on Their Household Budgets. Also - "Highlights"

- Low-Income Consumers' Energy Bills and Energy Savings In 2003 and FY 2004

- Forecast Energy Bills and Burdens of Low-Income Consumers in the 4 Largest States: FY 2006 v. 2001 with Normalized Weather

\section{Dissemination and Training, by Audience NASCSP/W.A.P.TAC}

Oct 2002 - W.A.P. Data systems and Reports

Feb 2003 - Project Resources for State Managers 
Feb 2004 - Project Resources for State Managers

Oct 2004

- CAA Network Capacity Indicators

- Project Resources for State Managers

Feb 2007

- Leveraging Best Practices

- Woodstove Change-out Opportunities

Sep 2007

- Project Resources for State Managers

- When States Support Leveraging: The Payback

US DOE National W.A.P. Conferences

2003

- Best Practices in Utility Leveraged Programs

- Impact of W.A.P. on Low-Income Bills

- Introduction to Project Resources

- Results National W.A.P. Leveraging

2005

- Low-Income Housing Condition and Implications for W.A.P.

- Low-Income Consumer Avoided Costs from W.A.P.

- Facilitated discussion group on "W.A.P.-Plus" integrated data systems

National Association of State Utility Consumer Advocates

Nov 2002 - Low-Income Consumer Bills and Hardships

Nov 2004 - Residential Energy Consumers and Federal Regulatory Policy

National Low-Income Energy Consortium

Jun 2004

- How to Find and Use National Energy Data

- Making Ends Meet

Jun 2005- Housing Quality and Inability to Pay Energy Bills

US DOE Regional Conferences - Includes Tasks II.3 (Warm Climate Leveraging

Support) and Tasks III (Local Reporting Systems)

Oct 2004

- Mid-Atlantic - W.A.P. Data Systems

- Mid-Atlantic - Report on Leveraging Survey

Oct 2006

- Southeast - Energy Bills and Burdens

- Southeast - SE Region Leveraging Opportunities

New York Low-Income Forum on Energy

Nov 2002

- Best Practices in Leveraged Programs

- NY Low-Income Energy Bills

National Community Action Foundation Energy Leveraging Conference 2005

- Introduce Project Resources

- Low-Income Consumer Bills, W.A.P. Impact

2006 - Introduce Project Resources

2007- Introduce Project Resources

American Gas Association Low-Income Committee

Mar 2006 - Low-Income Bills and Burdens and Leveraged Program Options

Forum on "Powering Arkansas" sponsored by AR PSC

Apr 2006

- Warm State Consumer Bills and W.A.P. Potential

- Best Practices in Utility-W.A.P. programs

American Association for Blacks in Energy, Florida Chapter 
Dec 2006 - SE Region Low-Income Programs: Options for Leveraged Resources

Energy Coordinating Agency, Philadelphia

Nov 2006-Options for coordinating efficiency, payments, and other low-income investments

Healthy Homes and Lead Alliance

Jun 2004 - W.A.P. and Healthy Houses

Mississippi State W.A.P. Training

Feb 2002

- Warm state consumer needs and efficiency investment options

- Best practices in leveraged utility programs

- Unusual sources of W.A.P. leveraging funds

American Public Gas Association Convention

Sep 2005 - Results of integrating efficiency and payment support investments for low-income consumers

ACEEE

Mar 2006 - Organized the workshop "Weatherization Assistance and Market Transformation"

\section{Task I.3 - Quick Responses for DOE}

EIA team for RECS and HHS/LIHEAP office. Written Comments and subsequent discussion on changes to household survey items.

2003-2006 - Annual briefing on warm state leveraging

2004, 2005, and 2007 - Participated in Millennium Committee meetings and outreach activities.

2006 HQ request - Reports tracking new W.A.P. leveraged resources - Jan - April Annual HQ request - Add local leveraged resources if known to NASCSP state survey 2007 HQ/ORNL - Requested EOS select local test sites for evaluation survey and mobilize participation

\section{Task II - Leveraged Programs Best Practices and Dissemination}

\section{Tasks II.1 and II.2 - Leveraged Programs Best Practices / Good Practices Materials}

- How to Pay for W.A.P. and Other Leveraging Advocacy

- PAYBACK! Or: Rewards for States that Support Leveraging Activities to Build Utility Partnerships

- Starting From Scratch: Winning Utility Funding For Weatherization-Related Investments

- New Leveraged Contributions: FY 2006 Energy Affordability Programs

- Weatherization Plus: Other Efficiency and Housing Investments Delivered by Local Weatherizers in PY 2000 (2003)

- Introduction to Best Practices in W.A.P./ Utility Energy Efficiency Programs or: Lessons Learned the Long Way (2004)

- Demand Side Management Programs = Weatherization Partnership Opportunities, 2005 (2007 update)

- The Community Weatherization Study: How Three Weatherization Agencies Implemented Programs Now Dubbed "Weatherization-Plus" (2001)

- Should Weatherization Assistance Program Delivery Agencies Leverage their Skills by Offering Services to the Private Market? (2007)

W.A.P. Plus Utilities: The Index of Key Programs \& (Mini Case Studies of) Their Features

- Features: Maryland's Electric Universal Service Program (EUSP)

- Features of Oregon Low-Income Efficiency Programs

- Idaho New Program Features And How They Were Won

- Program Features: Columbia Gas of Ohio WarmChoice

- Program Features: NV W.A.P. 


\section{Task III - Local Data (2002-2004) and Direct Assistance to State and Local}

\section{Leveraging (2002-2007)}

These are published or distributed materials. Many other reports and memos have been provided as noted in the summary. NETL has received copies of these less formal materials without guaranteed reports.

- Intro: Using NE Energy Data (2002) - a memo to VT CAAs

- Talking Points to SE Utility Commissions (2006) - a memo to FL DCD

- AR Program Options - for AR CAA Association

- Sales and Excise Taxes as Leveraged Resources (2007) - a memo for AR CAA

- Financing Natural Gas Energy Efficiency for TN - a memo for ACEEE 